\title{
Could Interventional Radiological Therapies Offer a Safer Alternative as We Emerge from COVID-19 Pandemic?
}

\author{
Shuvro H. Roy-Choudhury ${ }^{1,2}$ Gireesh Warawdekar ${ }^{3}$ \\ 1Department of Interventional Radiology, Rabindranath Tagore \\ Institute of Cardiac Sciences, NH Group of Hospitals, Kolkata, \\ West Bengal, India \\ 2Department of Radiology, University Hospitals of North Midlands, \\ Stoke-On-Trent, United Kingdom \\ ${ }^{3}$ Department of Interventional Radiology, Lilavati Hospital, Mumbai, \\ Maharashtra, India
}

J Clin Interv Radiol ISVIR:2020;4:184-188

\begin{abstract}
Address for correspondence Shuvro H. Roy-Choudhury, MBBS, FRCS, FRCR, EBIR, FCIRSE, Department of Interventional Radiology, Rabindranath Tagore Institute of Cardiac Sciences, NH Group of Hospitals, Kolkata 700099, West Bengal, India (e-mail: imagingandintervention@gmail.com).
\end{abstract}

\begin{abstract}
The ongoing SARS-CoV-2 (COVID-19) pandemic poses a major risk to health care delivery all around the world and also poses significant risks to the public and health care workers (HCWs). Surgical procedures, particularly elective procedures, have been cancelled or deferred due to increased risks associated with surgery and anesthesia both to the patient and the HCWs as well as to allocate resources to treat infected patients. This is particularly true for patients with comorbidities and cancer. As countries emerge from this pandemic, a phased return to conventional surgical procedures is being proposed, with emphasis on procedures performed in ambulatory settings and avoiding endotracheal intubation, where possible. Interventional radiological (IR)

Keywords

- SARS N-CoV 19

- interventional radiology

- elective surgery procedures offer a unique advantage in this setting, as these procedures are often performed with local or regional anesthesia with shorter hospital stay. In this brief communication, we outline the current opinion on surgical risks and guidelines and suggest areas where interventional therapies may offer an advantage to the multidisciplinary team and patient.
\end{abstract}

SARS-CoV-2 (COVID-19) is a pandemic due to a novel RNA coronavirus that originated in Wuhan, China, and has spread to most countries in the world. It is a highly contagious aerosol-borne viral illness with a high-infectivity rate, endangering health care workers (HCWs) in health care settings. At the time of writing, there are 7 million cases worldwide with 403,000 reported deaths associated with it. India has over 250,000 cases which are concentrated in the major metropolitan cities that also happen to be the major health care hubs. ${ }^{1}$ This has had a major impact on routine health care delivery, particularly in the setting of surgical procedures. Although the advice is continually changing and dependent on regional circumstances and guidelines, most surgical associations, ${ }^{2-4}$ Center for
Medicare and Medicaid service ${ }^{5}$ in the US as well as the Government of India, ${ }^{6}$ have recommended that all nonessential planned surgeries and procedures be limited until further notice. The best modeled estimate was that $28,404,603$ operations would be cancelled or postponed during the peak 12 weeks of disruption due to COVID19 , including 580,000 in India. The overall 12 -week cancellation rate would be $72.3 \%$. Globally, $81.7 \%$ of benign surgery and $37.7 \%$ of cancer surgeries are likely to be postponed. ${ }^{7}$ All elective procedures are canceled in England for at least 3 months, ${ }^{8}$ and it would take considerable time (11 months, even if throughput is increased by $20 \%$ ) and resources ( 2 billion GBP) to make up for lost time. ${ }^{8}$ published online 6-Jul-2020
DOI https://doi.org/

10.1055/s-0040-1714312 ISSN 2457-0214.
(C)2020. Indian Society of Vascular and Interventional Radiology.

This is an open access article published by Thieme under the terms of the Creative Commons Attribution-NonDerivative-NonCommercial-License, permitting copying and reproduction so long as the original work is given appropriate credit. Contents may not be used for commercial purposes, or adapted, remixed, transformed or built upon. (https://creativecommons.org/licenses/by-nc-nd/4.0/). Thieme Medical and Scientific Publishers Pvt. Ltd. A-12, 2nd Floor, Sector 2, Noida-201301 UP, India 
The reasoning behind these guidelines are manifold and quite compelling.

1. Possibility of viral contamination to staff during surgery, either open, laparoscopic, or robotic, should be considered and full protection should be worn regardless of the COVID status of the patient. Laparoscopy and electrocautery has been shown to cause aerosolization of bloodborne viruses such as hepatitis B, papilloma virus, and HIV. ${ }^{9-11}$ Although aerosolization during surgery has not been reported during the current pandemic, such transmission of SARS-CoV-2 cannot be neglected, as it is capable of being viable in aerosols for 3 hours. ${ }^{12}$ Use of bipolar devices and ultrasonic dissectors should therefore be minimized. Similarly, endoscopists may be at greater risk of viral exposure from endoscopy and airway procedures. ${ }^{4}$

2. Although improving, there are continuing resource constraints both in terms of personal protective equipment (PPE), ventilators, intensive care availability as well as appropriately trained staff. In the setting of the pandemic, the primary responsibility of health care providers remain the care of critically ill patients afflicted with COVID-19 infection, with less available resources for less urgent surgeries.

3. Intubation and extubation are high aerosol-generating procedures and should ideally take place in a negative pressure room. Therefore, it appears that local/regional anesthesia should be preferred to invasive airway management, whenever possible, for elective procedures. Operating rooms should be appropriately filtered and ventilated, and such facilities may not be easily available up and down the country..$^{13}$

4. Any risk factor or comorbidity (e.g., age > 60 years, obesity, high blood pressure, cardiovascular disease, and diabetes) should be disqualifying conditions in the early phase of elective surgery resumption, as these features impart a higher mortality in patients with COVID-19. ${ }^{14}$ The patient is also at a higher risk from surgery and anesthesia if they are positive for COVID-19. A review of four reports of patients diagnosed with COVID-19 during the perioperative period suggested a 14/51 (27.5\%) postoperative mortality rate, severe, mostly pulmonic, complications, and exposure and transmission to HCW..$^{15}$ This additional risk should be informed during the consenting procedure, as patients may be asymptomatic at the time of surgery and the screening RT-PCR test may be negative in the early part of the illness. In line with this, recently, the COVID Surg Collaborative ${ }^{16}$ reported 30-day results of an international cohort study assessing postoperative outcomes in 1,128 adults with COVID-19 who were undergoing a broad range of surgeries (53.6\% men and $46.4 \%$ women; $19.0 \%$ aged $<50$ years, $31.3 \%$ aged $50-69$ years, and $49.5 \%$ aged $\geq 70$ years). SARS-CoV-2 infection was diagnosed postoperatively in more than two-thirds of the patients (71.5\%). The overall postoperative mortality at 30 days was $23.8 \%$ (268 of 1,128 patients). Pulmonary complications occurred in 577 (51.2\%) patients and 30-day mortality in these patients was $38.0 \%$ (219 of 577 ), accounting for $82.6 \%$ (219 of 265 ) of all deaths.
5. Patients with cancer face a triple jeopardy. First, they are twice more prone to contract the illness than the general population due to their frequent hospital visits, advanced age, poor functional status, and their immunocompromised state due to malignancy and anticancer therapy. ${ }^{17}$ Second, the case fatality in COVID-19 patients with cancer is higher (5.6\%) than the overall reported case fatality $(2.3 \%)$, as seen in a study of 72,314 patients from China. ${ }^{18}$ Cancer was associated with higher risk of severe events (i.e., admission to the intensive care unit, invasive ventilation, or death) seen in 7 of 18 patients (39\%) with cancer versus 124 of 1,572 patients (8\%) without cancer; $(p=0.0003) .{ }^{19}$ Synergy of cancer, surgery, and COVID-19 may all contribute to this high-mortality rate. Third, while there is a higher perioperative mortality in patients with COVID-19, delaying oncological surgery may also be associated with poorer outcomes and disease progression. Patients' conditions may deteriorate, worsening their quality of life, as they wait for rescheduled surgery. In malignancy, delayed surgeries may lead to several unnecessary deaths. ${ }^{17}$ In this setting, nonoperative treatments, without invasive ventilation and lesser pulmonary risks, may be more suitable to be chosen during this period. As an example, contrary to nonpandemic times, a microwave ablation of a $3 \mathrm{~cm}$ metastasis may be a more appropriate decision by a multidisciplinary team rather than a liver resection, even in a surgically fit patient.

Most current surgical guidelines suggest that resumption of surgical services should be done in a phased manner based on current and projected COVID-19 cases in the facility and region, supply of PPE to the facilities, staffing availability, bed availability, especially ICU beds, ventilator availability, health and age of the patient, and urgency of the procedure. ${ }^{2-4}$ The American College of Surgeons have proposed an elective surgery acuity scale (ESAS) to enable decisions about recommencement of planned surgery by considering six case scenarios based on: a) the clinical urgency, b) prevalence of COVID-19 in the hospital, and c) health status of the patient. ${ }^{20}$ There are suggestions to perform elective procedures in an ambulatory care setting whenever possible in four of these six patient tiers. Although not specifically addressed in this document, it is worth noting that most interventional procedures are performed in an ambulatory setting and does fulfil this requirement. Fibroid embolization for symptomatic uterine fibroids and prostatic artery embolization for benign prostatic hypertrophy are good examples in this regard.

Interventional radiology (IR) therapies already offer treatment solutions with equivalent results to more invasive surgery in several disease conditions and organ systems. In certain conditions, these therapies are equally curative, while, in other conditions, they offer temporizing solutions till more definitive surgery. Detailed comparative analysis is beyond the scope of this article. In the background of an ongoing pandemic, some of these therapies may become even more appropriate (-Table 1) in the multidisciplinary setting with several advantages: 
Table 1 Suggested list of clinical conditions where currently surgery or endoscopy is the current gold standard and IR can offer an effective solution

\begin{tabular}{|c|c|c|c|}
\hline Disease condition & Surgical treatment & IR treatment & Remark \\
\hline Significant carotid artery stenosis & Carotid endarterectomy & Carotid stent & Definitive and curative \\
\hline Benign thyroid nodule & Thyroid lobectomy & Thyroid ablation & Definitive and curative \\
\hline Pleural empyema & Decortication & $\begin{array}{l}\text { Staged percutaneous drainage } \\
\text { and fibrinolytic therapy }\end{array}$ & Mostly definitive \\
\hline $\begin{array}{l}\text { Small lung tumor (primary or } \\
\text { metastatic) }\end{array}$ & $\begin{array}{l}\text { Lobectomy, segmentectomy or } \\
\text { metastatectomy }\end{array}$ & Lung tumor ablation & Definitive, for small tumors only \\
\hline Small hepatocellular carcinoma & $\begin{array}{l}\text { Liver transplantation, Surgical } \\
\text { resection }\end{array}$ & Ablation, TACE, TARE & $\begin{array}{l}\text { Usually definitive. Can be used } \\
\text { as temporizing therapy prior to } \\
\text { surgery or transplant }\end{array}$ \\
\hline Limited liver metastasis & Liver resection & Ablation, DEB-TACE, TARE & $\begin{array}{l}\text { Usually definitive. Can be used } \\
\text { as temporizing therapy prior to } \\
\text { surgery or transplant }\end{array}$ \\
\hline Small kidney tumor (T1) & Partial nephrectomy & Percutaneous renal ablation & Definitive and curative \\
\hline $\begin{array}{l}\text { All biliary obstruction including } \\
\text { in distal CBD }\end{array}$ & ERCP stent insertion & PTC and stenting & Definitive and palliative \\
\hline Acute unresolving cholecystitis & Cholecystectomy & Percutaneous cholecystostomy & Temporizing \\
\hline Enteral feeding & PEG insertion & RIG insertion & Definitive and palliative \\
\hline Urinary obstruction & $\begin{array}{l}\text { Cystoscopic ureteric stent } \\
\text { insertion }\end{array}$ & $\begin{array}{l}\text { Nephrostomy, percutaneous } \\
\text { ureteric stent }\end{array}$ & Usually temporizing \\
\hline Aortic aneurysm & Open aortic repair & EVAR & Definitive and curative \\
\hline Aortoiliac occlusion: TASC C, D & Aortofemoral grafts & Aortoiliac stents & $\begin{array}{l}\text { Definitive but potentially inferior } \\
\text { long-term result }\end{array}$ \\
\hline $\begin{array}{l}\text { Uterine fibroids and } \\
\text { adenomyosis }\end{array}$ & Myomectomy & Uterine artery embolization & Definitive and curative \\
\hline Benign prostatic hypertrophy & $\begin{array}{l}\text { TURP/other transurethral } \\
\text { procedures }\end{array}$ & Prostatic artery embolization & Definitive and curative \\
\hline Grade 3 hemorrhoids & Banding, hemorrhoidectomy & $\begin{array}{l}\text { Hemorrhoidal artery } \\
\text { embolization }\end{array}$ & Definitive but scant evidence \\
\hline Long SFA occlusions & Femoropopliteal graft & Angioplasty $+/ \square$ stent & $\begin{array}{l}\text { Definitive but potentially inferior } \\
\text { long-term result }\end{array}$ \\
\hline Knee osteoarthritis: Grade 3 & Total knee replacement & $\begin{array}{l}\text { Local injections, genicular } \\
\text { embolization }\end{array}$ & $\begin{array}{l}\text { Scant evidence but at least } \\
\text { temporizing }\end{array}$ \\
\hline
\end{tabular}

Abbreviations: CBD, common bile duct; DEB, drug-eluting bead; ERCP, endoscopic retrograde cholangiopancreatography; EVAR, endovascular aortic repair; IR, interventional radiology; PEG, percutaneous endoscopic gastrostomy; PTC, percutaneous transhepatic cholangiography; RIG, radiologically inserted gastrostomy; SFA, superficial femoral artery; TACE, transarterial chemoembolisation; TARE, transarterial radioembolization; TASC, Intersociety consensus for the management of peripheral arterial disease; TURP, transurethral resection of prostate.

a) IR therapies usually do not require invasive ventilation, reducing risk to the anesthetist as well as less risk of pulmonary complications in asymptomatic COVID-19 patients. A joint statement from the American and European Societies of Regional Anesthesia and Pain therapy states that regional anesthesia should be used in preference to general anesthesia in patients to reduce aerosol generation and reduce opioid-related respiratory compromise. ${ }^{21}$

b) There is no risk of surgical smoke and aerosol-related HCW infection.

c) The shorter hospital stay related to IR therapies reduces the risk of acquiring an infection for both the patient and the HCW.

d) The IR operator (e.g., at the wrist or groin) may well be further away from the patient's nose and mouth and be at less risk than in conventional surgeries. This is, however, a supposition, as there is no available data on rate of infections amongst physicians based on specialty. A carotid stent as opposed to an endarterectomy is a good example in this regard. Coiling of intracranial aneurysms has not been included in this list as it most often requires a general anesthesia. But, even here, the location of the operator is further away from the airway when compared with a craniotomy.

e) In certain scenarios (e.g., in fibroid embolization versus myomectomy, liver resection versus ablation), the relevant IR procedure may be shorter in duration, thereby reducing the risk of transmission.

f) Most IR procedures can be performed by a single operator, as opposed to the larger surgical team required for equivalent surgical therapies.

g) Some procedures may be performed at the bedside, reducing the risk of transmission from a COVID-19 positive patient, for example, abscess drainage.

h) These advantages are particularly relevant in patients with cancer facing the triple jeopardy mentioned earlier, 
that is, IR offering an effective treatment to cure or prevent disease progression, without exposing the patient or the HCW to excessive risks. Emerging consensus statements are already beginning to reflect this thought, for example, treatment of Barcelona Clinic Liver Cancer A primary liver cancer with locoregional therapies. ${ }^{22}$

Although there is, as yet, no evidence of increased IR workload during the pandemic, ${ }^{23}$ there are interesting snippets in the current guidelines. An urology review suggests use of ureteric stents or nephrostomy tubes under local anesthesia to be considered first in urinary tract obstruction or infection. ${ }^{24}$ The American College of Surgeons sugges $t^{25}$ nonoperative treatment of common urgent surgical conditions such as appendicitis, cholecystitis, and diverticulitis, including antibiotics or nonsurgical intervention as the mainstay of therapy. Therefore, drainages and cholecystostomy may need to be performed increasingly to avoid anesthetic risks. We feel that this argument should be extended further to include even elective therapies such as in fibroids, prostate, thyroid, hemorrhoids, or knee osteoarthritis.

On the other hand, the availability of IR resources as well as the cost of IR procedures in certain health care settings could be a limiting factor. The conditions mentioned in - Table 1 may not at all be suitable for IR procedures and a case-by-case consideration by the multidisciplinary team should be performed. Nonurgent conditions would need to be deferred, but may still be very helpful over the next year as health care facilities face the burden of canceled elective cases. Finally, although less risky, the possibility of infection of a scarce resource such as IR personnel need to be considered and all relevant precautions need to be taken.

Wider dissemination of IR procedures has suffered from lack of public, patient and physician awareness. The current pandemic could be an occasion for IR to step up to fill a void to offer safer therapies and help our multidisciplinary colleagues at the time of a crisis. Procedures will, of course, need to be performed with adequate precautions and safety considerations, as outlined in local guidelines and recommendation by IR societies. ${ }^{26,27}$ With severe travel restrictions, local IR services may be called upon to deliver these therapies. These new referral pathways and increased patient confidence can result in improved service delivery that may outlast the pandemic. IR teams across the globe are already showing their adaptability and versatility in the setting of heavy COVID-19 caseload health care settings, ${ }^{28}$ sharing intensive care responsibility, performing bedside procedures, inserting lines, etc. Now, more than ever, the patients and the multidisciplinary teams should be given the choice of the benefits offered by IR therapies, and interventional radiologists should embrace this situation by offering their skills and services to the wider community both during as well as during the emergence from the pandemic.

\section{Conflicts of Interest}

Both authors have no conflicts to disclose.

\section{References}

1 Worldometer. Coronavirus updates. Available at: https://www. worldometers.info/coronavirus/. Accessed June 7, 2020

2 American College of Surgeons. COVID-19: guidance for triage of non-emergent surgical procedures. Available at: https:// www.facs.org/covid-19/clinical-guidance/triage. Accessed May 31,2020

3 Royal College of Surgeons of England. Good practice for surgeons and surgical teams.. Available at: https://www.rcseng. ac.uk/standards-and-research/standards-and-guidance/goodpractice-guides/coronavirus/covid-19-good-practice-for-surgeons-and-surgical-teams/. Accessed May 31, 2020

4 Pryor A. Society of American Gastrointestinal and Endoscopic Surgeons (SAGES) and EAES recommendations regarding surgical response to COVID-19 crisis. Available at: https://www. sages.org/recommendations-surgical-response-covid-19. Accessed May 31, 2020

5 Centers for Medicare and Medicaid Services. CMS adult elective surgery and procedures recommendations. Available at: https://www.cms.gov/files/document/covid-elective-surgery-recommendations.pdf. Accessed May 31, 2020

6 MoHFW. Advisory for hospitals and medical education institutions. Ministry of Health and Social Welfare, Government of India. Available at: https://www.mohfw. gov.in/pdf/AdvisoryforHospitalsandMedicalInstitutions. pdf. Accessed June 5, 2020

7 Nepogodiev D, Bhangu A; COVIDSurg Collaborative. Elective surgery cancellations due to the COVID-19 pandemic: global predictive modelling to inform surgical recovery plans. Br J Surg 2020; (e-pub ahead of print). doi:10.1002/bjs.11746

8 Iacobucci G. Covid-19: all non-urgent elective surgery is suspended for at least three months in England. BM] 2020;368:m1106

9 Kwak HD, Kim SH, Seo YS, Song KJ. Detecting hepatitis B virus in surgical smoke emitted during laparoscopic surgery. Occup Environ Med 2016;73(12):857-863

10 Sawchuk WS, Weber PJ, Lowy DR, Dzubow LM. Infectious papillomavirus in the vapor of warts treated with carbon dioxide laser or electrocoagulation: detection and protection. J Am Acad Dermatol 1989;21(1):41-49

11 Johnson GK, Robinson WS. Human immunodeficiency virus-1 (HIV-1) in the vapors of surgical power instruments. J Med Virol 1991;33(1):47-50

12 van Doremalen N, Bushmaker T, Morris DH, et al. Aerosol and surface stability of SARS-CoV-2 as compared with SARSCoV-1. N Engl J Med 2020;382(16):1564-1567

13 Cook TM, El-Boghdadly K, McGuire B, McNarry AF, Patel A, Higgs $A$. Consensus guidelines for managing the airway in patients with COVID-19: Guidelines from the Difficult Airway Society, the Association of Anaesthetists the Intensive Care Society, the Faculty of Intensive Care Medicine and the Royal College of Anaesthetists. Anaesthesia 2020;75(6):785-799

14 Mouton C, Hirschmann MT, Ollivier M, Seil R, Menetrey J. COVID-19 - ESSKA guidelines and recommendations for resuming elective surgery. J Exp Orthop 2020;7(1):28

15 Nahshon C, Bitterman A, Haddad R, Hazzan D, Lavie O. Hazardous postoperative outcomes of unexpected COVID19 infected patients: a call for global consideration of sampling all asymptomatic patients before surgical treatment. World J Surg 2020; (e-pub ahead of print). doi:10.1007/ s00268-020-05575-2

16 COVIDSurg Collaborative. Mortality and pulmonary complications in patients undergoing surgery with perioperative SARS-CoV-2 infection: an international cohort study. Lancet 2020;(e-pub ahead of print). doi:10.1016/ S0140-6736(20)31182-X 
17 Al-Shamsi HO, Alhazzani W, Alhuraiji A, et al. A practical approach to the management of cancer patients during the novel Coronavirus disease 2019 (COVID-19) pandemic: an international collaborative group. Oncologist 2020;25(6):e936-e945

18 Ueda M, Martins R, Hendrie PC, et al. Novel Coronavirus Pneumonia Emergency Response Epidemiology Team. The epidemiological characteristics of an outbreak of 2019 novel coronavirus diseases (COVID-19) in China. Liu Xing Bing Xue Za Zhi 2020;41:145-151

19 Liang W, Guan W, Chen R, et al. Cancer patients in SARSCoV-2 infection: a nationwide analysis in China. Lancet Oncol 2020;21(3):335-337

20 American College of Surgeons. COVID-19: Guidance for Triage of Non-Emergent Surgical Procedures. Available at: https://www. facs.org/covid-19/clinical-guidance/triage. Accessed May 31, 2020

21 American Society of Regional Anesthesia and Pain Medicine. Practice recommendations on neuraxial anesthesia and peripheral nerve blocks during the COVID-19 pandemic. A Joint Statement by the American Society of Regional Anesthesia and Pain Medicine (ASRA) and European Society of Regional Anesthesia and Pain Therapy (ESRA) Available at: https://www.asra.com/page/2905/ practice-recommendations-on-neuraxial-anesthesia-and-peripheral-nerve-blocks-dur. Accessed June 13, 2020

22 Barry A, Apisarnthanarax S, O'Kane GM, et al. Management of primary hepatic malignancies during the COVID-19 pandemic: recommendations for risk mitigation from a multidisciplinary perspective. Lancet Gastroenterol Hepatol 2020; (e-pub ahead of print). doi:10.1016/S2468-1253(20)30182-5

23 Cahalane AM, Cui J, Sheridan RM, et al. Changes in interventional radiology practice in a tertiary academic center in the United States during the Coronavirus disease 2019 (COVID-19) pandemic. J Am Coll Radiol 2020; (e-pub ahead of print). doi: 10.1016/j.jacr.2020.05.005

24 Puliatti S, Eissa A, Eissa R, et al. COVID-19 and urology: a comprehensive review of the literature. BJU Int 2020;125(6):E7-E14

25 American College of Surgeons. COVID-19 guidelines for triage of emergency general surgery patients. Available at: https:// www.facs.org/covid-19/clinical-guidance/elective-case/emergency-surgery. Accessed May 31, 2020

26 De Gregorio MA, Guirola JA, Magallanes $\mathrm{M}$, et al; COVID-19-IRSpain. COVID-19 Outbreak: Infection Control and Management Protocol for Vascular and Interventional Radiology Departments-Consensus Document. Cardiovasc Intervent Radiol 2020; (e-pub ahead of print). doi:10.1007/s00270-020-02493-7

27 Zhu Y, He Y, Wang Z, et al Chinese Society of Interventional Radiology Expert Consensus on the Prevention and Control of COVID-19 in Interventional Radiology Procedures (First Edition). Quant Imaging Med Surg 2020;10(5):1045-1057

28 Manna S, Voutsinas N, Maron SZ, et al. Leveraging IR's adaptability during covid-19: a multicenter single urban health system experience. J Vasc Interv Radiol 2020;31(7):1192-1194 